\title{
Research on the Vehicle Loads and Their Effect on the Medium and Small Span Highway Girder Bridges
}

\author{
Yongjun NI \\ School of Civil Engineering \\ Beijing Jiaotong University \\ Beijing, China \\ e-mail: yjni@bjtu.edu.cn
}

\author{
Jinzhu GU \\ Business Division 1 \\ China International Engineering Consulting Corporation \\ Beijing, China \\ e-mail: Gujinzhu_2010@163.com
}

\begin{abstract}
The uniform loading pattern is specified in the General Code for Design of Highway Bridges and Culverts (JTG D60-2015) and its former version in China. In recent years, bridge safety accident due to the heavy commercial trucks occurred and reported occasionally. Whether the design loads specified in the existing code could satisfy the bridge safety in the heavy load areas is a highlighted question. Through the 24hour traffic investigation at Xinghe segment of G6 Highway insitu, the statistical analysis respecting to the vehicle types, vehicle numbers and the distribution of vehicles spaces are carried out. The commercial trucks weight is investigated at a typical coal storage site close to G6 Highway road. Based on the investigation data, the load patterns of the routine vehicle teams and the congestion vehicle teams are developed and proposed. Choosing the simply supported and continuous girder bridges as the case bridges, the finite element models were established using MIDAS/Civil software. The load effects under the routine vehicle team load and the congestion vehicle team load are analyzed considering 2 lanes and 3 lanes, respectively. The calculating results were compared and analyzed with the results from the coded loads in 2 lanes and 3 lanes. It was shown from the comparing analysis that the congestion vehicle team load is the potential danger for the existing bridge. The bridge design should consider the regional traffic characteristics and its development.
\end{abstract}

Keywords-bridge engineering; heavy traffic; traffic investigation; vehicle load model; bending moment

\section{INTRODUCTION}

The General Code for Design of Highway Bridges and Culverts (JTG D60-2015) follow the loading pattern in the Code (JTG D60-2004), namely that the combination of the uniformly distributed load and a concentrated load in China. Whether the newly issued code is suitable for the typical areas with heavy traffic load is a highlighted question in the highway field.

The design load criterion of the vehicle for highway bridges continuously attracts extensive attention. Based on the investigation data, Andrzej S. Nowak (1993) proposed the vehicle load models for the routine vehicle teams and the congestion vehicle teams. The load spectrum for the highway bridge was constructed by Tong Le-wei (1994). In 1997, the distribution rules of the vehicle load were developed in China. The similar distribution rule was also found by T. J. Miao (2001) based on the WIM investigation data. Four methods to calculate the vehicle load value of highway bridges were proposed by Liang Yu-zhao (2010). Zhang Xigang (2014) systematically analyzed and summarized the adaptability and the research methods of the vehicle load criterion for highway bridges.

Overloading is the primary reason of the bridge failure under the serving loading. Based on the data from WIM system, Liang Dong (2011) generated the simulation traffic load flow. Having compared the bending moment between the normal traffic load and the simulation traffic load flow, the live load criterion for the heavy traffic was defined. The amplification factors of the live load were also proposed for different overload conditions.

Based on the traffic load information recorded in the Health Monitoring System in Shaoxing section in G104 Road, Xuanhua section in Xuanda Highway and Shaihai section in Hushan Highway, the inertial forces effects for 5 simply supported $\mathrm{T}$ girder beam were calculated, the relation between the stiffness and strength of the case bridges with the characteristics of the overload vehicles were analyzed by Chen An-yang (2014).

It is shown that the distribution rule of the vehicle load significantly varied with the different areas. The vehicle type and loading capacity are greatly changed in recent years. The new vehicle load criterion should be constructed to catering the rapid development of the vehicles and traffic volume for the different areas.

\section{ANALYSIS ON VEHICLE LOAD INVESTIGATION}

The investigations are classified as the traffic volume investigation in 24 hours and the targeted investigation for the congestion vehicles. The mileage of K273+600 of G6 Highway is selected as the case segment to investigate the actual traffic volume in 24 hours. The targeted investigation for the congestion vehicle respecting to the vehicle type and the vehicle distances are carried out in the near road in G0601 Highway.

\section{A. Statistics of Vehicle Type}

The vehicles are classified as the car and mini vans, bus, two-axle truck, three-axle truck, four-axle truck, five-axle truck and six-axle truck. The statistical results are shown in Table I. 
TABLE I. STATISTICS FOR DISTRIBUTION OF VEHICLES TYPES

\begin{tabular}{ccccc}
\hline Vehicle Type & \multicolumn{2}{c}{ 24 hours investigation in 2013 } & Investigation in 2011 & Investigation in 2012 \\
\hline & Vehicle numbers & Vehicle proportion & Daily average & Daily average \\
\hline Cars and mini vans & 838 & $10.71 \%$ & 934 & 1298 \\
Bus & 120 & $1.53 \%$ & 742 & 188 \\
Two-axle truck & 199 & $2.54 \%$ & 1741 & 1412 \\
Three-axle truck & 52 & $0.66 \%$ & 1223 & 289 \\
Four-axle truck & 88 & $1.13 \%$ & & 6347 \\
Five-axle truck & 22 & $0.28 \%$ & 6334 & 9534 \\
Six-axle truck & 6502 & $83.14 \%$ & 10974 & \\
Total number of vehicles & 7821 & $100.00 \%$ & & \\
\hline
\end{tabular}

It is shown in Table I that the traffic is very large up to 7821 vehicles in 24 hours. The most prominent vehicles are trucks with six axes up to $83.14 \%$. The daily average vehicle numbers decline greatly from 2011 to 2013. But the proportion of the trucks with five or six axes is increased gradually. The traffic load becomes heavier year by year.

\section{B. Statistics of Vehicles Spaces}

The vehicle space is an important factor to considering the vehicle load effect. During the investigation in-situ, the vehicle congestion was not occurred. The investigated vehicle space could be taken as the routine vehicle condition. Only the spaces shorter than $100 \mathrm{~m}$ are effective in the investigation. Those spaces greater than $100 \mathrm{~m}$ are classified as more than $100 \mathrm{~m}$. The investigated vehicle spaces are shown in Table II.

TABLE II. SPACE Distribution BETWEen VehicLES IN 24 Hours

\begin{tabular}{ccc}
\hline Vehicle spaces in meter & $\begin{array}{c}\text { Vehicle } \\
\text { numbers }\end{array}$ & $\begin{array}{c}\text { Proportion of } \\
\text { vehicle }\end{array}$ \\
\hline $0-10$ & 159 & $2.03 \%$ \\
$10 \sim 20$ & 397 & $5.08 \%$ \\
$20 \sim 30$ & 613 & $7.84 \%$ \\
$30 \sim 40$ & 702 & $8.98 \%$ \\
$40 \sim 50$ & 798 & $10.20 \%$ \\
$50 \sim 60$ & 719 & $9.19 \%$ \\
$60 \sim 70$ & 597 & $7.63 \%$ \\
$70 \sim 80$ & 402 & $5.14 \%$ \\
$80 \sim 90$ & 276 & $3.53 \%$ \\
$90 \sim 100$ & 185 & $2.37 \%$ \\
$>100$ & 2489 & $31.82 \%$ \\
Overtaking or parallel & 484 & $6.19 \%$ \\
going & & $100.00 \%$ \\
\hline Total vehicle numbers & 7821 & \\
\hline
\end{tabular}

Not considering those data with vehicle spaces more than $100 \mathrm{~m}$ or the condition of overtaking or parallel running, the statistical data of vehicle spaces between 0 and $100 \mathrm{~m}$ accorded with the normal distribution, and can be fitted as:

$$
y=48.86+\frac{45558}{\sqrt{2 \pi} 49.13 / 2} e^{-\frac{1}{2}(x-50.98)^{2}}
$$

Where $y$ is the occurrence number of vehicles, and $x$ is the vehicle space in meter.

The vehicle spaces distribution is shown in Fig.1.

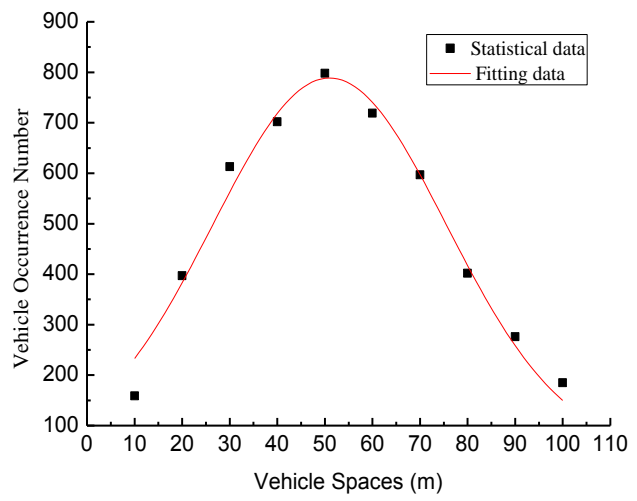

Figure 1. Fitting curve of vehicle space under routine running state

It is found that all vehicles are six-axle trucks under the vehicle congestion condition. All trucks are parking on the road with their spaces about $2 \mathrm{~m}$ or going slowly with the spaces as $3 \mathrm{~m}$ to $4 \mathrm{~m}$.

\section{Statistic of Vehicle Weight}

Due to the lack of the WIM equipment during the investigation, the vehicle weight cannot be obtained directly. Considering the similarity of the freight in trucks, the vehicle loads were investigated in a coal storage site near to the G6 highway. The investigated data are shown in Table III.

It can be shown from Table IV that all empty trucks weights are closed to $15 \mathrm{t}$, all loaded trucks weights are closed to 55t. It is owing to the strict management measures in the investigation highway segment. 
TABLE III. STATISTICS FOR THE WEIGHTS OF COAL CONVEYOR VEHICLES

\begin{tabular}{cccccc}
\hline Number of Vehicle & $\mathbf{1}$ & $\mathbf{2}$ & $\mathbf{3}$ & $\mathbf{4}$ & $\mathbf{5}$ \\
Empty weight (t) & 15.66 & 16.14 & 15.98 & 15.96 & 15.56 \\
Loaded weight (t) & 55.34 & 55.38 & 55.72 & 55.68 & 55.52 \\
Number of Vehicle & $\mathbf{6}$ & $\mathbf{7}$ & $\mathbf{8}$ & $\mathbf{9}$ & $\mathbf{1 0}$ \\
Empty weight (t) & 15.78 & 15.78 & 14.94 & 15.9 & 15.38 \\
Loaded weight (t) & 55.32 & 55.48 & 55.18 & 55.5 & 55.54 \\
\hline
\end{tabular}

\section{VEHICLE MODEL}

\section{A. Load Model of Vehicle}

According to Limits of Dimensions, Axle Load and Masses of Road Vehicles, the total weight of the six-axle truck should be no more than $49 \mathrm{t}$. But only the total weight of the six-axle truck more than $55 \mathrm{t}$ is taken as the overload. The vehicle load models of the truck for $49 \mathrm{t}$ and $55 \mathrm{t}$ are shown in Fig.2, respectively.

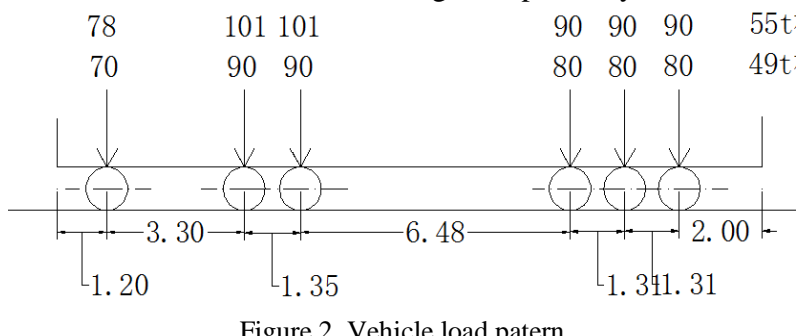

In Fig.2, the upper numbers mean the axle load in $\mathrm{kN}$, and the lower numbers mean the axle distance in meter.

\section{B. Load Model of Vehicle Team}

Based on the fitting function above mentioned, applying $5 \%$ guaranteed rate of the vehicles spaces, namely $10.54 \mathrm{~m}$, considering the overall dimension of the vehicles, the distance between the last axle of the former vehicle and the front axle of the latter vehicle is determined as $12 \mathrm{~m}$ under the condition of routine vehicle team. While under the condition of congestion vehicle team, the corresponding distance between the former and latter vehicle is determined as $4 \mathrm{~m}$. The constructed load patterns of the vehicle team are shown in Fig.3 and Fig.4. In Fig.3 and Fig.4, similarly, the upper numbers mean the axle load in $\mathrm{kN}$, and the lower numbers mean the axle distance in meter.

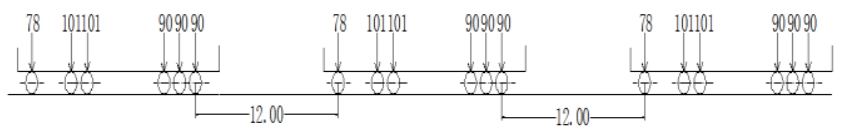

Figure 3. Load pattern of routine vehicle team

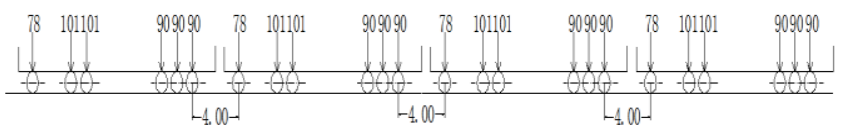

Figure 4. Load pattern of routine vehicle team

\section{LOAD EFFECT UNDER ACTUAL VEHICLES}

Some simply supported and continuous girder bridge with medium and small spans in Inner Mongolia areas are taken as the case bridges. The load effects results from the routine vehicle load and the congestion vehicle load are compared with those results from the highway level load.

\section{A. Basic Assumptions and Rules}

The beam-grid method is applied to construct the finite element model of the case bridge using Midas/Civil software. Using the influence line method, all vehicle axle loads are only loaded at the location where can obtain the maximum absolute value. The lateral reduction factor is not considered when applying the vehicle team load, while the impact coefficient of the live load is considered.

\section{B. Calculation of Simply Supported Girder Bridge}

The typical cored slab section (seen in Fig.5) is applied for the bridge spans as $10 \mathrm{~m}, 13 \mathrm{~m}$ and $16 \mathrm{~m}$. While the Tbeam section (seen in Fig.6) is applied for the bridge spans as $20 \mathrm{~m}, 25 \mathrm{~m}, 30 \mathrm{~m}$ and $40 \mathrm{~m}$. It is noticed that the beam height and the allocation of the transverse diaphragm are arranged according to the actual situation. All case bridges are loaded by the coded load, routine vehicle team load and congestion vehicle team load considering the different lane numbers, respectively. For saving paper, only the bending moment of the mid-span is listed below. The calculated bending moment and corresponding moment ratios are shown in Fig.7 and Fig.8.

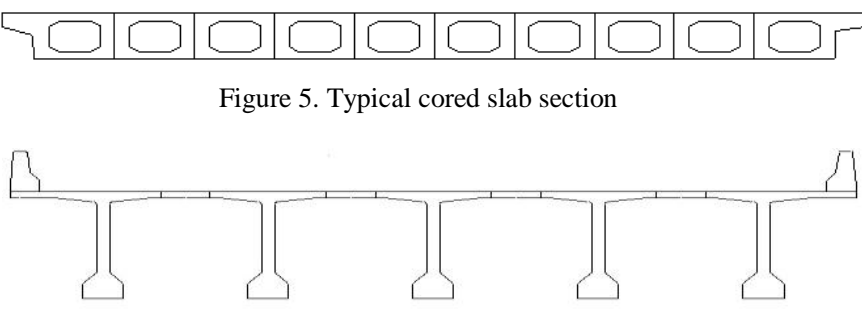

Figure 6. Typical T-Type girder bridge section

It can be shown in Fig.7 and Fig. 8 that the bending moment of the case bridges increase with the bridge spans. The bending moment curves show us the big jump from the cored beam to the T-type girder beam. It is results from the much longer span and much greater bearing capability of $\mathrm{T}$ type beam than the cored beam. The bending moments under the routine vehicle team load and the congestion vehicle load in two lanes are generally lower than those under the coded load. When the vehicles load in three lanes, some bending moments of the case bridges are greater than those in coded load. Especially for the bridge span with $40 \mathrm{~m}$, the ratio of bending moment effect is up to 1.41 , namely that the condition is not conservative or unsafe for the case bridge according to the Specification for Inspection and Evaluation of Load-bearing Capacity of Highway Bridges. 


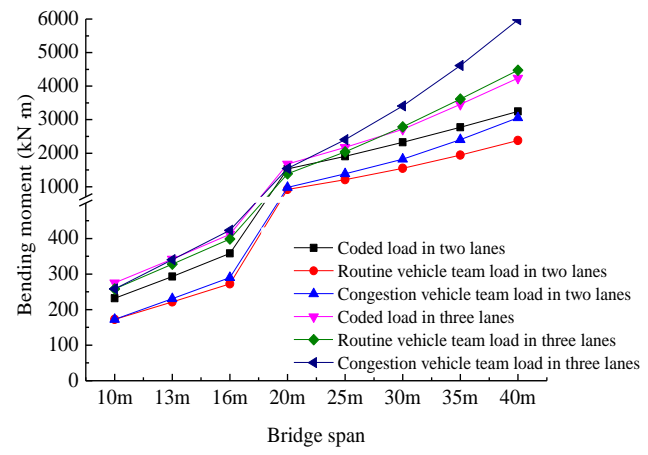

Figure 7. Bending moment of mid span

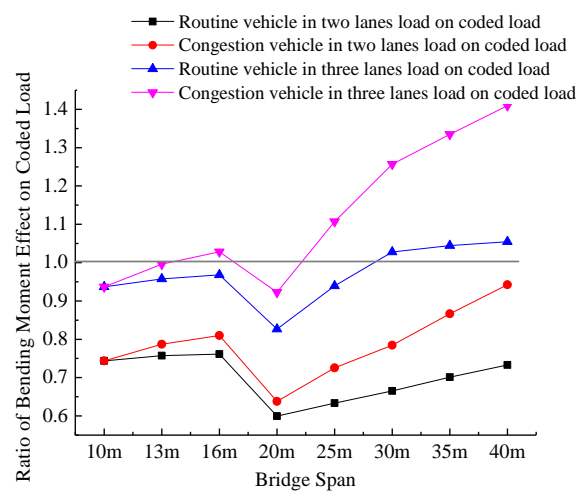

Figure 8 . Ratio of bending moment effect

\section{Calculation of Continuous Girder Bridge}

The continuous girder bridges models are constructed using Midas/Civil software with the span arrangement as $3 \times 20 \mathrm{~m}, 3 \times 25 \mathrm{~m}, 3 \times 30 \mathrm{~m}, 3 \times 35 \mathrm{~m}$ and $3 \times 40 \mathrm{~m}$. The box-girder beams are prefabricated. The transverse diaphragm of the box girder is arranged according to the actual situation. All case bridges are loaded by the coded load, routine vehicle team load and congestion vehicle team load considering the different lane numbers, respectively. For saving paper, only the bending moments at the fixed bearing and the mid-span of the second span are listed below. The calculated bending moment and corresponding moment ratios at fixed bearing are shown in Fig.10 and Fig.11, while those results at midspan are shown in Fig.12 and Fig.13.

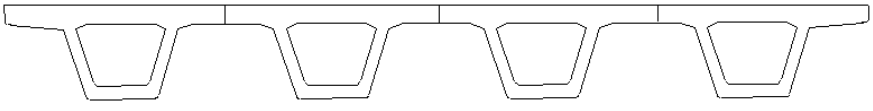

Figure 9. Typical box section of continuous girder bridge

It can be shown from Fig.9 and Fig.11 that the bending moments at the fixed bearing under the vehicle loads are significantly greater than those under the coded load. It is noticed that all the ratios of bending moment on coded load are greater than 1.05. The maximum ratio of bending moment on coded load is up to 2.12 for the case bridge arrangement $3 \times 40 \mathrm{~m}$ under the congestion vehicle team load in three lanes. It can be concluded that the case bridges under the congestion vehicle load are not safe according to the Specification for Inspection and Evaluation of Load-bearing Capacity of Highway Bridges.

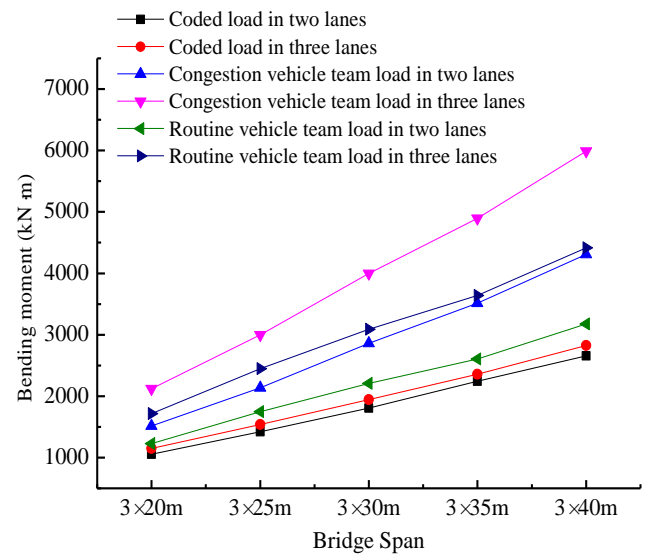

Figure 10. Bending moment of seating

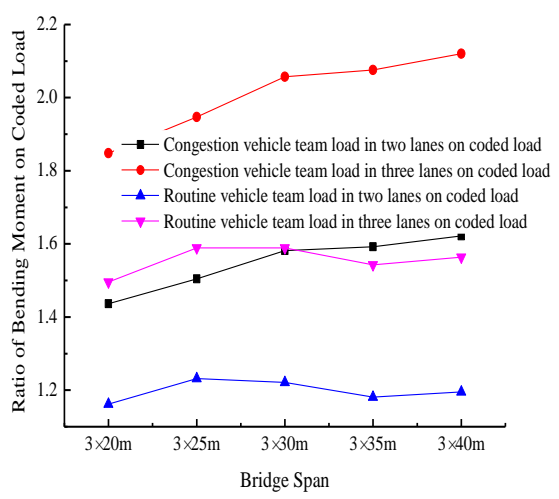

Figure 11. Ratio of bending moment effect of seating

It can be shown from Fig.12 and Fig.13 that the bending moments at the mid-span of the second span under the vehicle loads in two lanes are lower than those under the coded load. While those results from the congestion vehicle team loads in three lanes are slightly greater than those under the coded load. The maximum ratio of bending moment on coded load is up to 1.224 for the case bridge arrangement $3 \times 40 \mathrm{~m}$ under the congestion vehicle team load in three lanes. It can be concluded that the case bridges under the congestion vehicle load are not conservative according to the Specification for Inspection and Evaluation of Load-bearing Capacity of Highway Bridges. 


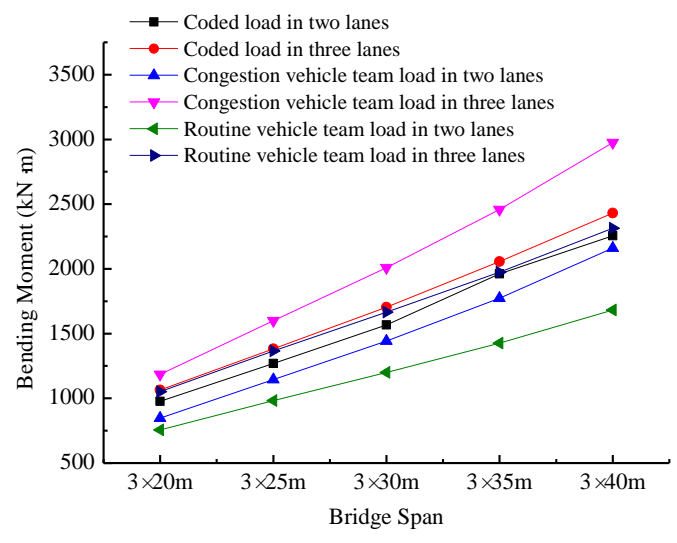

Figure 12. Bending moment of mid span

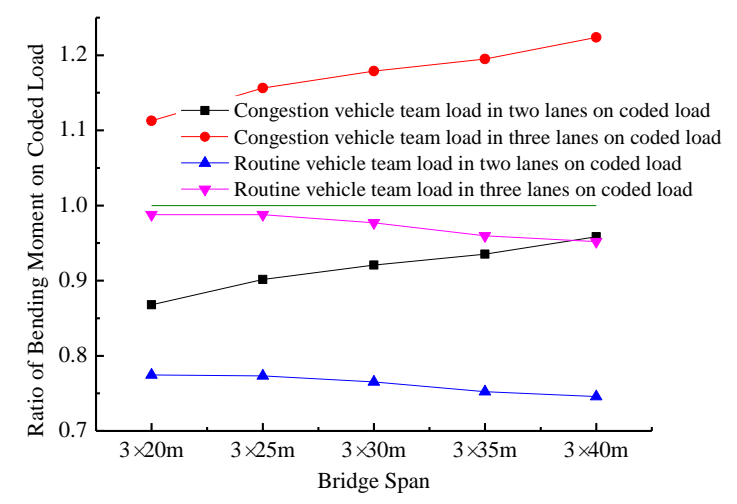

Figure 13. Ratio of bending moment effect

\section{CONCLUSIONS}

(1) The heavy commercial truck is the predominant vehicle type in the investigated segment of the G6 Highway, especially for the truck with six axles, which traffic proportion is up to $83.14 \%$ in the 24 hour investigation. The design vehicle load pattern should consider the regional characteristics and its development.

(2) The distribution of the vehicle space for the routine vehicle team accords with the normal distribution.

(3) The load patterns for the routine and congestion vehicle team based on the investigation can be used as the check load to check the bearing capacity of the existing bridges.

(4) For the simply supported bridge, the ratios of the bending moment at mid-span under the vehicle team load on coded load increase with the bridge span. The maximum of the ratio is up to 1.41 for the bridge span $40 \mathrm{~m}$ under the congestion vehicle team load in three lanes, that is greatly bigger than 1.05 according to the Specification for Inspection and Evaluation of Load-bearing Capacity of Highway Bridges. It means that the congestion vehicle is the potential danger to the simply supported bridge.
(5) For the continuous girder bridge, the ratios of the bending moment at fixed bearing under the vehicle team load on coded load increase with the bridge span. In the special case of the bridge span arrangement $3 \times 40 \mathrm{~m}$ under the congestion vehicle team load in three lanes, the maximum ratio of the bending moment at the fixed bearing is up to 2.12 , the maximum ratio of the bending moment at the mid-span of the second span is up to 1.224 . These values are greatly bigger than 1.05 according to the Specification for Inspection and Evaluation of Load-bearing Capacity of Highway Bridges. It means that the congestion vehicle is very dangerous for the continuous girder bridge. The design of the continuous girder bridge must consider the regional vehicle rule to check the bearing capacity.

(6) Due to the lack of the detailed traffic investigation, the vehicle pattern proposed in this paper need to be verified. The rational vehicle load pattern should be specified considering the regional traffic characteristics and its development.

\section{ACKNOWLEDGMENT}

This research was supported by the Construction of Science and Technology Project of Ministry of Communication (No.2013318J06200) and Basic Research Project of Beijing Jiaotong University (No. 2012JBM087). Authors acknowledge the cordial help of IMSH for the data support and the investigation in -situ.

\section{REFERENCES}

[1] General Code for Design of Highway Bridges and Culverts (JTG D60-2015) [S], 2015, Beijing: China Communications Press.

[2] General Code for Design of Highway Bridges and Culverts (JTG D60-2004) [S], 2004, Beijing: China Communications Press.

[3] Andrzej S. Nowak. Live load model for highway bridges [J]. Structural Safety, 1993, 13(1): 53-66.

[4] Tong Le-wei, Shen Zu-yan and Chen Zhong-yan. Fatigue load spectrum for urban road bridges [J]. China Journal of Civil Engineering Society, 1997, 30(5): 20-27.

[5] Highway bridge vehicle load research team. Highway bridge vehicle load research [J]. Highway, 1997, No.3, 8-12.

[6] Miao T.J, Chan T.H.T. Bridge live load models from WIM data [J]. Engineering Structures, 2002, Vol.24, 1071-1084.

[7] Liang Yu-zhao, Calculation Method for Characteristic Value of Vehicle Load for Highway Bridges [D]. Master Degree Dissertation of Chang'an University, 2010.12.

[8] Zhang Xi-gang, Research on Vechile Load Criterion for Highway Bridges [M], 2014.7, Beijing: China Communications Press.

[9] Liang Dong, Dong Chun-xia, Zhao Shao-wei and Chen Pei. Research on Load Standard of Highway Bridges Suitable for Heavy Load Traffic [J], Highway, 20111, No.3, 30-35.

[10] Chen An-yang, Safety Evaluation and Research for Response Characteristics of Prefabricated Simply Supported T-Beam Bridges under Heavy Traffic Multi-Region, Master Degree Dissertation of Changan University, 2014.6.

[11] Limits of Dimensions, Axle Load and Masses of Road Vehicles (GB1589-2004) [S], 2012.8, Beijing: China Standard Press.

[12] Specification for Inspection and Evaluation of Load-bearing Capacity of Highway Bridges (JTG/T J21-2011) [S]. 2011.10, Beijing: China Communications Press. 